\title{
EVALUATION OF ADAPTABILITY OF THREE DIFFERENT ROOT CANAL SEALERS. (IN VITRO STUDY)
}

\author{
Tariq Yehia Abdelrahman*, Menna Allah Ali Abdeldaiem*, Maram Farouk Obeid***
}

\begin{abstract}
Introduction: This study aimed to compare Guttaflow bioseal, MTA-Fillapex, and AH plus with regards to their adaptability on dentin surface.

Methods: Thirty $(n=30)$ single rooted human teeth were instrumented and divided into three groups according to the type of sealer used (each $n=10$ ). All root canals were obturated with lateral compaction technique. Roots were cut longitudinally and evaluated for adaptability using scanning electron microscope (SEM) at 1500x. Five readings were taken for the widest gap distances at the three thirds of the root for each specimen.
\end{abstract}

Results: AH plus group showed less mean values of gap distances than the other groups at apical and middle two thirds, while GuttaFlow bioseal mean gap distance was less at the coronal one third. MTA-F group showed the higher mean values among the three thirds of the root with no significant difference.

Conclusion: AH plus showed superior adaptability than GuttaFlow bioseal, while the worst was MTA-Fillapex.

KEYWORDS Adaptability, GuttaFlow bioseal, Sealer-dentine interface.

\section{INTRODUCTION}

Root canal sealers are necessary for forming a bond between the obturating core material and the root canal wall, sealing off of voids, accessory canals, apical ramifications, and multiple foramina. Thus the interface between sealer and dentin is critical ${ }^{1,2}$. However, adaptability of sealer on dentin interface without voids depends on sealer's physical properties ${ }^{3}$. Although sealing ability of root canal filling material represents a great challenge for endodontists, there is no standardized test for sealing ability that applies to ISO 6876:2001 ('Dental root canal sealing materials) till now. Thus, many studies analyzed sealer dentin interface using SEM as an indication of sealing ability. ${ }^{4}$

\footnotetext{
* Lecturer of Endodontics, Faculty of Dentistry, Ain Shams University

** MSc of Endodontics, Faculty of Dentistry, Ain Shams University

*** Associate Professor of Endodontics, Faculty of Dentistry, Ain Shams University
} 
AH Plus is an epoxy-resin sealer which was developed more than 50 years ago and is well known for its good adaptation on dentin wall ${ }^{5}$. It has been shown to have excellent flow characteristics, and good adhesion ${ }^{6}$. The sealer sets through addition polymerization which guarantees long-term dimensional stability. ${ }^{7}$ MTA Fillapex (Angelus, Londrina, PR, Brazil) is MTA based endodontic sealer that contains $13 \%$ MTA and $38 \%$ resin in its composition $^{8}$. MTA fillapex has been shown to have higher values of solubility than accepted values of American National Standards Institute/American Dental Association (ANSI/ADA) specifications as claimed by Borges et al, FariaJunior et al, Viapiana et al. ${ }^{2}$ GuttaFlow Bioseal (Coltène/Whaledent, Langenau, Germany) was introduced in market in 2015 as a new advancement of Guttaflow 2. Coltene claims that in addition to its bioactive property, Guttaflow Bioseal also has slight setting expansion which ensure maximum seal ${ }^{9}$. It was reported that GuttaFlow Bioseal has good physicochemical properties regarding setting time, solubility, radiopacity, flow $^{10}$ in addition to its high penetration to dentin ${ }^{11}$.

\section{MATERIALS AND METHODS}

Thirty extracted human mandibular incisors with no signs of internal or external resorption were used. Teeth were decoronated at the level of cementenamel junction using diamond disc mounted in a low speed hand piece under water coolant to standardize roots length at $13 \mathrm{~mm}$. Size $15 \mathrm{~K}$ file was used to assure patency of the canal and the apical foramen. The working length was established by subtracting $1 \mathrm{~mm}$ from the length obtained when the file tip just appeared at the apical foramen. Root canals were instrumented using ProTaper Universal rotary files * up to F4. Irrigation with $2 \mathrm{ml}$ of $2.5 \% \mathrm{NAOCL}^{* *}$ and $17 \%$ EDTA $^{* * *}$ was done, then final rinse with saline was performed. All teeth were divided randomly into three groups according to the sealer used for obturation; Group (A) GuttaFlow bioseal group, group (B) MTA Fillapex group, and group (C) AH plus group. MTA Fillapex sealer and AH plus sealer were mixed according to the manufacturer's instructions, while GuttaFlow bioseal was injected into root canals.

Roots were obturated with lateral compaction technique using master cone size 40 taper $2 \%$; quality of obturation has been assessed by standardized radiographs, specimens containing voids have been excluded. All roots were kept in $100 \%$ humidity at $37^{\circ} \mathrm{C}$ for 24 hours to ensure complete setting of sealers. Roots were cut into 2 longitudinal sections and evaluated for adaptation of the sealer on the dentinal wall using scanning electron microscope at magnification $x 1500$. Five readings were taken at the widest gaps in each third of the root then mean value was calculated. Data were collected, tabulated and statistically analyzed using SPSS $^{\circledR}$ Software $^{* * * *}$.

\section{RESULTS}

The analysis of the interaction between sealer and root dentin has been assessed using SEM. All materials showed gap containing and gap-free regions along the interface between sealer and dentin. In most of the AH plus samples gap free regions were observed more .Widest gaps distance between sealer and dentin at each third of the root

\footnotetext{
* Dentsply, Maillefer, Switzerland

** Clorox Egypt.

*** META BIOMED CO, Ltd., ChungbukKorea.

**** SPSS, Version 25, Inc., an IBM Company, NY, USA.
} 
were measured on SEM micrographs and mean was calculated. Mean and Standard deviation (SD) values for comparison between groups were presented in table (1) and figure (1). According to mean values $\mathrm{AH}$ plus showed superior adaptation on dentin walls followed by GuttaFlow Bioseal then MTA Fillapex. Statistically there was no significant difference between groups ( $\mathrm{P}$-value $>0.001)$.

TABLE (1) Comparison of Gap distance between groups.

\begin{tabular}{|c|c|c|c|c|c|}
\hline & & Apical & Middle & Coronal & $\begin{array}{c}\mathbf{P} \\
\text { (within group) }\end{array}$ \\
\hline \multirow{3}{*}{ GuttaFlow Bioseal } & Mean & 5.19 & 4.07 & .88 & \multirow{3}{*}{$.247 n s$} \\
\hline & Std. Deviation & 4.23 & 5.58 & 1.96 & \\
\hline & Median & 4.52 & .00 & .00 & \\
\hline \multirow{3}{*}{ MTA-F } & Mean & 8.60 & 8.04 & 6.07 & \multirow{3}{*}{$.368 \mathrm{~ns}$} \\
\hline & Std. Deviation & 12.83 & 7.97 & 6.20 & \\
\hline & Median & 4.52 & .00 & .00 & \\
\hline \multirow{3}{*}{ AH Plus } & Mean & .38 & .00 & 1.19 & \multirow{3}{*}{$.368 n s$} \\
\hline & Std. Deviation & .85 & .00 & 2.65 & \\
\hline & Median & .00 & .00 & .00 & \\
\hline \multicolumn{2}{|c|}{$\mathbf{P}$ (between groups) } & $.186 n s$ & $.138 n s$ & $.165 n s$ & --- \\
\hline
\end{tabular}

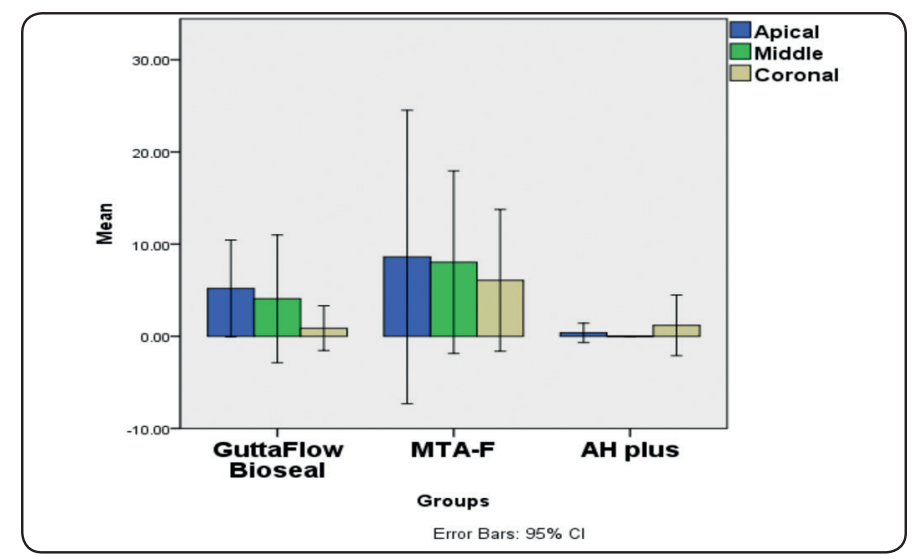

Fig. (1) Bar chart showing mean gap distance among groups. 


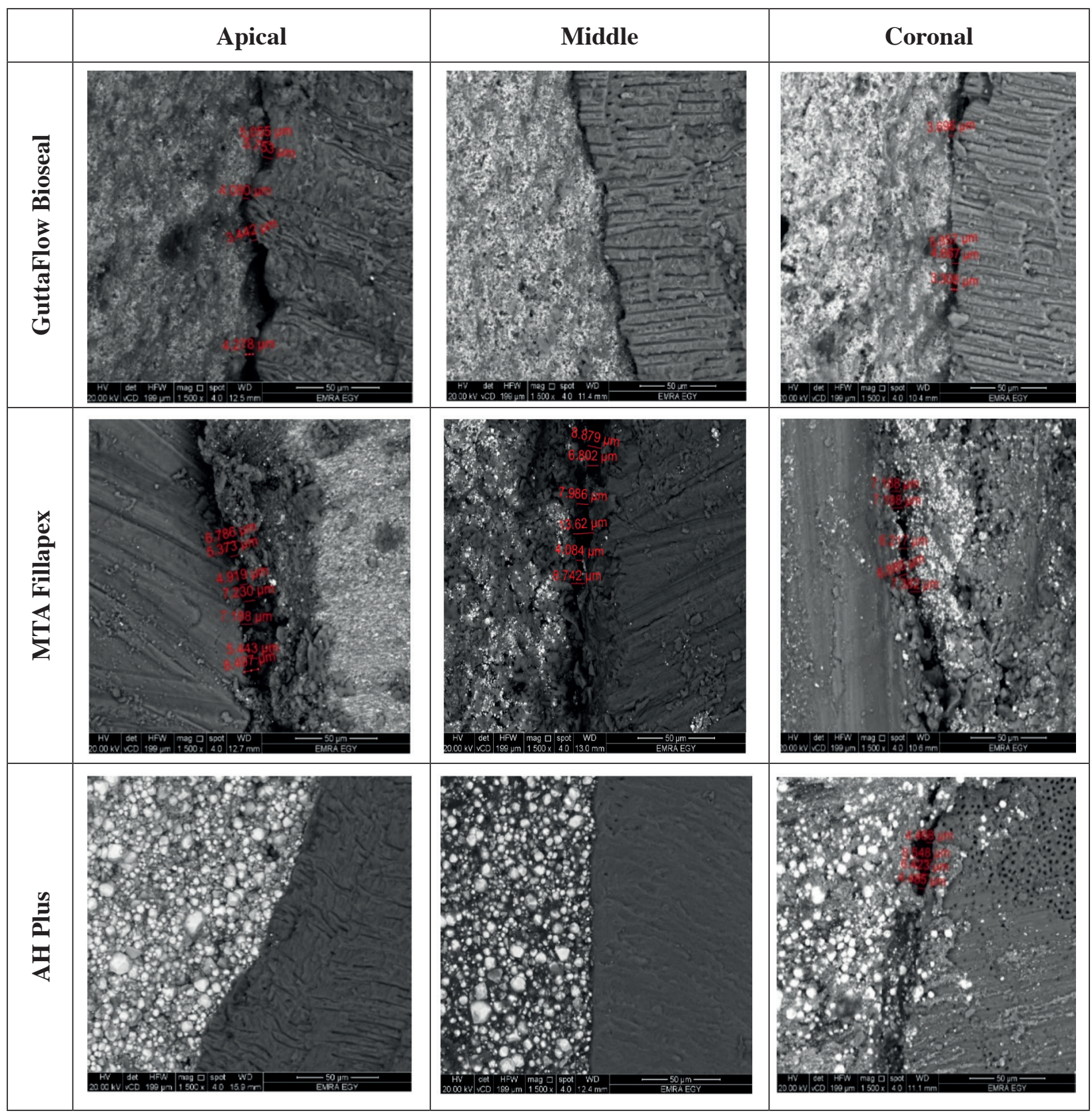

Fig. (2) SEM micrographs showing measurements of gap distance between sealer and dentin. 


\section{DISCUSSION}

The most common reason of failure of root canal treatment is bacterial invasion from filled root canals into the periapical tissues, thus a perfectly tight seal should be obtained in order to block the pathway of communication between root canal systems and periradicular tissues and gurantee long term success ${ }^{12}$. A strict cleaning protocol of the root canals was done before obturation. The instrumented root canals were flushed with EDTA gel after copious irrigation with NAOCL in order to remove smear layer. Smear layer adversely affect adhesion of sealers to dentin and increase the presence of gaps at sealer-dentin interface ${ }^{13,14}$. Longitudinal root sections were scanned under SEM for measurement of gaps distance along sealer dentin interface. For the sake of accuracy, readings of the largest gap distance were measured and mean gap distance was calculated at each third of the root ${ }^{15}$. Results revealed the presence of both gap-free regions and gap-containing region in canals filled with the three materials, overall AH plus sealer was superior to GuttaFlow bioseal at apical and middle thirds, while GuttaFlow Bioseal showed better adaptation at the coronal one third without a statistically significant difference. Our results are in agreement with studies held by Amoroso-silva et $\mathbf{a l}^{2}$, Sevimay et al ${ }^{16}$ which stated that AH plus sealer was the best sealer regarding adaptability on dentin surface when compared with other sealers. This can be explained by the fact that epoxy resin present in AH Plus can react with the amine group of the collagen network and create a covalent bond between sealer and dentin ${ }^{4}$. On the other hand Zhang et $\mathbf{a l}^{17}$ stated that $\mathrm{AH}$ plus sealer was equivalent in adaptability to the bioceramic sealer, IRoot SP. Low adaptability of MTA-F on root dentin may be related to its chemical composition, in which the resinous component may adversely affect its bonding behavior ${ }^{18}$.

\section{CONCLUSION}

GuttaFlow Bioseal showed less adaptability on dentin wall than the gold standard $\mathrm{AH}$ plus while the worst was MTA-Fillapex.

\section{REFERENCES}

1. Al-Haddad A, Che Ab Aziz ZA. Bioceramic-Based Root Canal Sealers: A Review. Int J Biomater. 2016; 2016:9753210. doi:10.1155/2016/9753210

2. Andr P, Amoroso-Silva ES, Martini B, et al. Microscopic Analysis of the Quality of Obturation and Physical Properties of MTA Fillapex. Microsc Res Tech. 2014; 77:1031-1036. doi:10.1002/jemt.22432

3. Salz U, Poppe D, Sbicego S, Roulet J-F. Sealing properties of a new root canal sealer. Int Endod J. 2009;42(12):10841089. doi:10.1111/j.1365-2591.2009.01635.x

4. Tedesco M, Cristina M, Felippe S, et al. Adhesive Interface and Bond Strength of Endodontic Sealers to Root Canal Dentine After Immersion in Phosphate-Buffered Saline. Microsc Res Tech. 2014;77:1015-1022. doi:10.1002/ jemt. 22430

5. Marciano MA, Guimarães BM, Ordinola-Zapata R, et al. Physical Properties and Interfacial Adaptation of Three Epoxy Resin-based Sealers. J Endod. 2011;37(10):14171421. doi:10.1016/j.joen.2011.06.023

6. McMichen FRS, Pearson G, Rahbaran S, Gulabivala K. A comparative study of selected physical properties of five root-canal sealers. Int Endod J. 2003;36(9):629-635.

7. Silva Almeida LH, Moraes RR, Morgental RD, Pappen FG. Are Premixed Calcium Silicate-based Endodontic Sealers Comparable to Conventional Materials? A Systematic Review of In Vitro Studies. J Endod. 2017;43(4):527-535. doi:10.1016/j.joen.2016.11.019

8. Almeida LH, Gomes APN, Gastmann AH, et al. Bone tissue response to an MTA-based endodontic sealer, and the effect of the addition of calcium aluminate and silver particles. Int Endod J. 2019. doi:10.1111/iej.13135

9. ROEKO GuttaFlow® bioseal. https://www.coltene.com/ products/endodontics/obturation-amp-sealing-materials/ roeko-sealers/roeko-guttaflowR-bioseal/. Accessed April 19, 2019.

10. Tanomaru-Filho M, Torres FFE, Chávez-Andrade GM, et al. Physicochemical Properties and Volumetric Change 
of Silicone/Bioactive Glass and Calcium Silicate-based Endodontic Sealers. J Endod. 2017;43(12):2097-2101. doi:10.1016/j.joen.2017.07.005

11. Akcay M, Arslan H, Durmus N, Mese M, Capar ID. Dentinal tubule penetration of AH Plus, iRoot SP, MTA fillapex, and guttaflow bioseal root canal sealers after different final irrigation procedures: A confocal microscopic study. Lasers Surg Med. 2016;48(1):70-76. doi:10.1002/ lsm.22446

12. Moura-Netto C, Mello-Moura ACV, Palo RM, Prokopowitsch I, Pameijer CH, Marques MM. Adaptation and penetration of resin-based root canal sealers in root canals irradiated with high-intensity lasers. J Biomed Opt. 2015;20(3):038002. doi:10.1117/1 .JBO.20.3.038002

13. Sağsen B, Ustün Y, Pala K, Demırbuğa S. Resistance to fracture of roots filled with different sealers. Dent Mater J. 2012;31(4):528-532.

14. do Carmo SS, Néspoli FFP, Bachmann L, et al. Influence of early mineral deposits of silicate- and aluminate-based cements on push-out bond strength to root dentine. Int Endod J. 2018;51(1):92-101. doi:10.1111/iej.12791

15. Kim JR, Nosrat A, Fouad AF. Interfacial characteristics of Biodentine and MTA with dentine in simulated body fluid. J Dent. 2015;43(2):241-247. doi:10.1016/j. jdent.2014.11.004

16. Sevimay S, Kalayci A. Evaluation of apical sealing ability and adaptation to dentine of two resin-based sealers. J Oral Rehabil. 2005;32(2):105-110. doi:10.1111/j.13652842.2004.01385.x

17. Zhang W, Li Z, Peng B. Assessment of a new root canal sealer's apical sealing ability. Oral Surgery, Oral Med Oral Pathol Oral Radiol Endodontology. 2009;107(6):e79-e82. doi:10.1016/j.tripleo.2009.02.024

18. Assmann E, Scarparo RK, Böttcher DE, Grecca FS. Dentin Bond Strength of Two Mineral Trioxide Aggregatebased and One Epoxy Resin-based Sealers. J Endod. 2012;38(2):219-221. doi:10.1016/j.joen.2011.10.018 